\title{
Edukasi Kesehatan Cegah Hiperkolesterolemia Berdasarkan Pola Hidup Masyarakat Kelurahan Muara Fajar Timur, Pekanbaru
}

\author{
Aisyara Yuliandari ${ }^{1 *}$, Early Regita Wahyu Safrija ${ }^{2}$, Sri Devi Era Purba ${ }^{3}$ \\ ${ }^{123}$ Akademi Kesehatan John Paul II Pekanbaru - Labuh Baru Barat Kecamatan Payung Sekaki Pekanbaru \\ *E-mail: aisyara@akjp2.ac.id No. HP 085363352124
}

Received: 20 Mei 2021; Revision: 20 Juni 2021; Accepted: 04 Agustus 2021

\begin{abstract}
Abstrak
Penyakit kardiovaskular merupakan penyakit yang tidak menular yang menjadi penyebab kematian nomor satu didunia setiap tahunnya. Salah satu penyebab terjadinya penyakit kardiovaskular adalah tingginya kadar kolesterol darah yaitu $>200 \mathrm{mg} / \mathrm{dL}$. Kadar kolesterol dapat dipengaruhi oleh berbagai faktor seperti konsumsi makanan tinggi lemak. Pemeriksaan kolesterol dan pemberian edukasi hiperkolesterolemia diikuti oleh 38 orang masyarakat Kelurahan Muara Fajar Timur Pekanbaru. Peserta yang mengikuti kegiatan ini seluruhnya berjenis kelamin wanita dengan usia > 30 tahun. Kegiatan ini dilakukan dengan pemeriksaan kolesterol menggunakan alat tes digital dan pemberian edukasi kesehatan cegah hiperkolesterolemia. Hasil yang diperoleh dari pemeriksaan kolesterol terhadap seluruh peserta didapatkan sebanyak 76,32 \% atau 29 orang peserta memiliki kadar kolesterol > 200 $\mathrm{mg} / \mathrm{dl}$. Berdasarkan edukasi, pengisian angket dan wawancara yang dilakukan, bahwa sebagian besar masyarakat tidak memahami akan bahayanya hiperkolesterolemia. Pemberian edukasi terkait hiperkolesterolemia kepada masyarakat, dilakukan untuk meningkatkan kesadaran masyarakat agar menjaga pola hidup yang sehat.
\end{abstract}

Kata kunci: Hiperkolesterolemia; Kolesterol; Penyakit kardiovaskular; Pola hidup

\begin{abstract}
Cardiovascular disease is a non-communicable disease which the number one cause of death globally every year. One of the causes of cardiovascular disease is high cholesterol levels $>200 \mathrm{mg} / \mathrm{dL}$. Cholesterol levels can be influenced by various factors such as the consumption of high-fat foods. The cholesterol examination and the provision of hypercholesterolemia education were attended by 38 participants of Muara Fajar Timur Urban Village, Pekanbaru. Participants who attended community service activities were all women with age $>30$ years. This community service is carried out by checking cholesterol using a digital cholesterol test kit and providing health education to prevent hypercholesterolemia. The results obtained from a cholesterol examination of all participants were found to be $76.32 \%$ or 29 participants had cholesterol levels $>200 \mathrm{mg} / \mathrm{dL}$. Based on education, filling out questionnaires and interviews conducted, that most of the Muara Fajar Timur communities do not understand the dangers of hypercholesterolemia. The provision of hypercholesterolemia education to the Muara Fajar Timur communities was carried out to increase public awareness in maintaining a healthy lifestyle.
\end{abstract}

Keyword: Cholesterol; Cardiovascular Disease; Hypercholesterolemia; Lifestyle

Yuliandari, A., Wahyu Safrija, E., \& Purba, S. (2021). Edukasi Kesehatan Cegah Hiperkolesterolemia Berdasarkan Pola Hidup Masyarakat Kelurahan Muara Fajar Timur, Pekanbaru. Masyarakat Berdaya dan Inovasi, 2(2). doi:https://doi.org/10.33292/mayadani.v2i2.60

This is an open access article under the CC-BY-SA license.

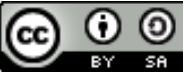

\section{PENDAHULUAN}

Penyakit kardiovaskular merupakan salah satu penyakit yang tidak menular yang menjadi penyebab kematian nomor satu didunia setiap tahunnya (Wihastuti et al., 2016). Pravalensi penyakit kardiovaskular di Indonesia sebanyak 36 juta (Jempormase et al., 2016) dengan angka kematian secara mendadak sekitar 28,8 juta dan 18 juta penderita tidak menunjukkan gejala apapun (Setyaningrum et al., 2019). Penyakit kardiovaskular seperti penyakit jantung coroner, hipertensi dan stroke terjadi karena 
adanya gangguan pada fungsi jantung dan pembuluh darah (Setiadi \& Halim, 2018). Salah satu penyebab terjadinya gangguan pada fungsi jantung dan pembuluh darah adalah hiperkolesterolemia (Jempormase et al., 2016).

Hiperkolesterolemia merupakan merupakan salah satu penyakit degenerative yang mengganggu metabolisme kolesterol dalam darah sehingga kadar kolesterol darah melebihi batas normal yaitu >200 $\mathrm{mg} / \mathrm{dL}$ (Yani, 2015). Hiperkolesterolemia tidak menimbulkan gejala yang spesifik dan hanya dapat dideteksi dengan pemeriksaan kolesterol pada darah (Maryati, 2017). Kadar kolesterol yang tinggi memiliki korelasi dengan peningkatan risiko penyakit kardiovaskular dan obesitas (Subandrate et al., 2019). Semakin tinggi kolesterol maka semakin tinggi pula resiko terjadinya penyakit kardiovaskular (Setyaningrum et al., 2019). Kadar kolesterol dapat dipengaruhi oleh berbagai faktor seperti pola makan yang tidak sehat, kebiasan olah raga, jenis kelamin dan kebiasaan merokok (Budiatmaja \& Noer, 2014).

Pola makan yang buruk seperti kebiasaan mengkonsumsi makanan yang mengandung lemak jenuh yang tinggi dan kurangnya aktivitas tubuh seperti berolah raga dapat menyebabkan penumpukan lemak didalam tubuh (Herman et al., 2015). Makanan yang mengandung kolesterol, biasanya banyak terdapat pada daging kambing, daging babi dan jeroan. Masyarakat kelurahan Muara Fajar Timur Pekanbaru didominasi oleh etnis batak yang gemar mengonsumsi makanan tinggi lemak seperti daging babi. Kandungan lemak pada babi mencapai $100 \mathrm{~g} / 100 \mathrm{~g}$ lemak dan dapat menyebabkan terjadinya hiperkolesterolemia (Kumar et al., 2014). Sebagian besar masyarakat kelurahan Muara Fajar Timur tidak memahami bahayanya hiperkolesterolemia, sehingga perlu dilakukan edukasi dan skrining kesehatan pemeriksaan kolesterol. Upaya ini dilakukan untuk mengendalikan hiperkolesterolemia dan meningkatkan kualitas hidup masyarakat sehingga insiden penyakit kardivaskular dapat dicegah (Lina \& S Dian, 2019). Hal inilah yang menjadi dasar pengabdi untuk memberikan Edukasi Kesehatan Cegah Hiperkolesterolemia Berdasarkan Pola Hidup Masyarakat Kelurahan Muara Fajar Timur Pekanbaru.

\section{METODE}

Tahap pertama kegiatan pengabdian adalah tahap perencanaan yang dilakukan oleh tim pelaksana. Proses perencanaan awal mencakup identifikasi kebutuhan, penentuan jalan keluar dan kegiatan yang akan dilakukan, serta menyusun pengorganisasian kegiatan. Tahap awal kegiatan, tim pengabdi berkunjung dan berkoordinasi dengan pihak mitra yakni ketua RT dan RW Kelurahan Muara Fajar Timur Pekanbaru. Wawancara dilakukan kepada pihak mitra untuk mengidentifikasi kebutuhan yang diperlukan dalam kegiatan ini. Hasil kesepakatan dengan pihak mitra yakni dilakukan salah satu kegiatan memberikan edukasi kesehatan cegah hiperkolesterolemia berdasarkan pola hidup masyarakat kelurahan Muara Fajar Timur Pekanbaru.

Tahap kedua dari kegiatan ini adalah tahap persiapan yang meliputi pembuatan surat pengantar penyuluhan, pembuatan undangan pengabdian yang ditujukan kepada masyarakat kelurahan Muara Fajar Timur Pekanbaru, pembuatan spanduk, melengkapi daftar administrasi, persiapan materi pengabdian, menyiapkan bahan yang dibutuhkan untuk pelaksanaan kegiatan pemeriksaan kolesterol. 
Tahap ketiga dari kegiatan ini adalah tahap pelaksanaan kegiatan pengabdian yang dilakukan dengan pemeriksaan kolesterol menggunakan alat tes digital dan pemberian edukasi kesehatan cegah hiperkolesterolemia. Masyarakat yang datang untuk melakukan pemeriksaan kolesterol wajib mengisi data diri dan kuesioner yang telah disediakan oleh tim pengabdian. Masyarakat yang telah melakukan pemeriksaan kolesterol diberikan edukasi sesuai dengan tujuan pengabdian ini. Secara ringkas, tahapan kegiatan pengabdian disajikan pada gambar berikut.

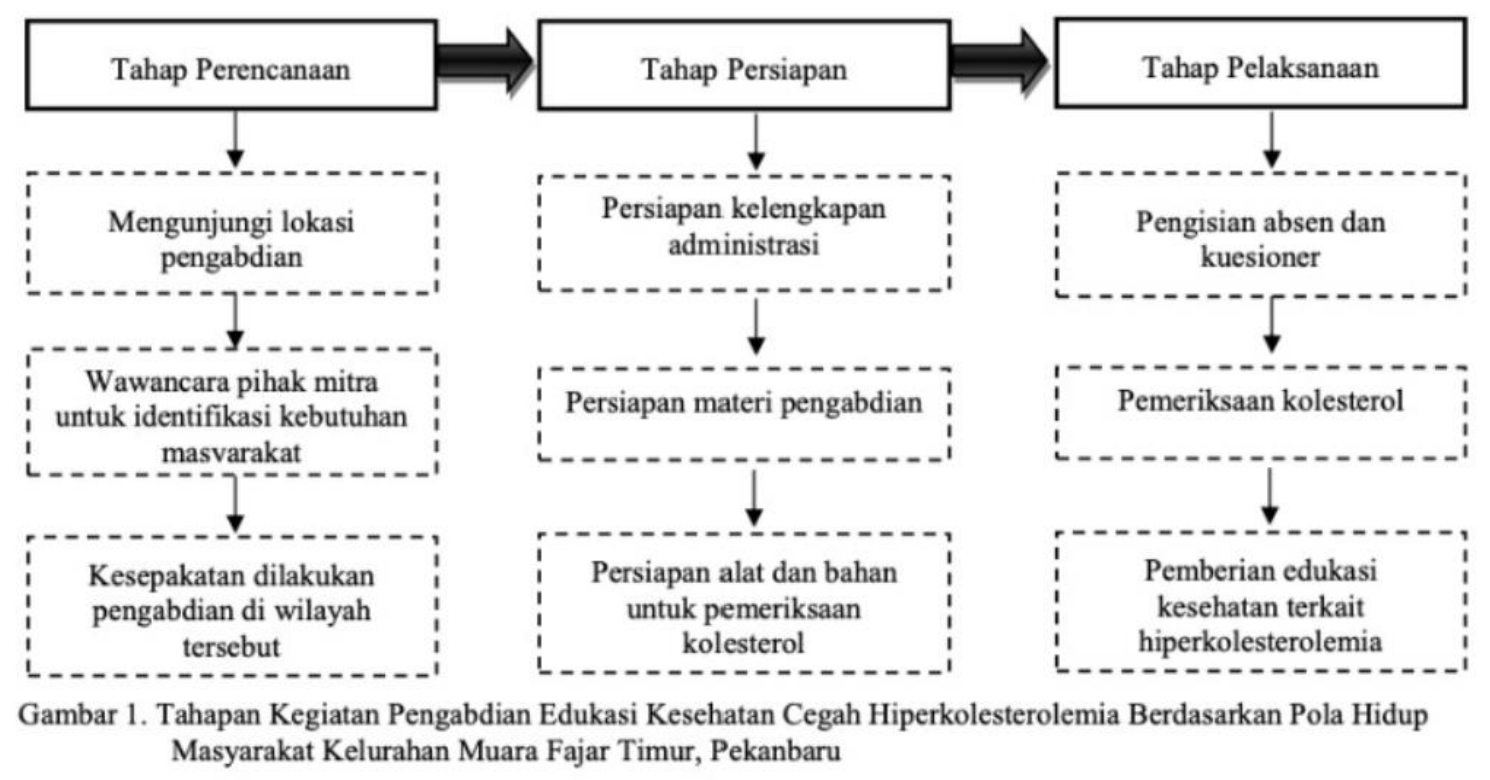

\section{HASIL DAN PEMBAHASAN}

Pengabdian masyarakat ini dilaksanakan dengan melakukan pemeriksaan kolesterol menggunakan alat tes digital. Pemberian edukasi terkait hiperkolesterolemia kepada masyarakat, dilakukan setelah pemeriksaan kolesterol. Masyarakat kelurahan Muara Fajar Timur sangat antusias mengikutikegiatanini,karenakegiataninimemberidampakpositifdilingkunganmereka. Halinidapat terlihat dari jumlah peserta yang mengisi kuisioner, mengikuti pemeriksaan kolesterol dan mengikuti pemberian edukasi hiperkolesterolemia yang dilaksanakan oleh tim. Kegiatan pengabdian tersaji pada Gambar 1 dan Gambar 2.

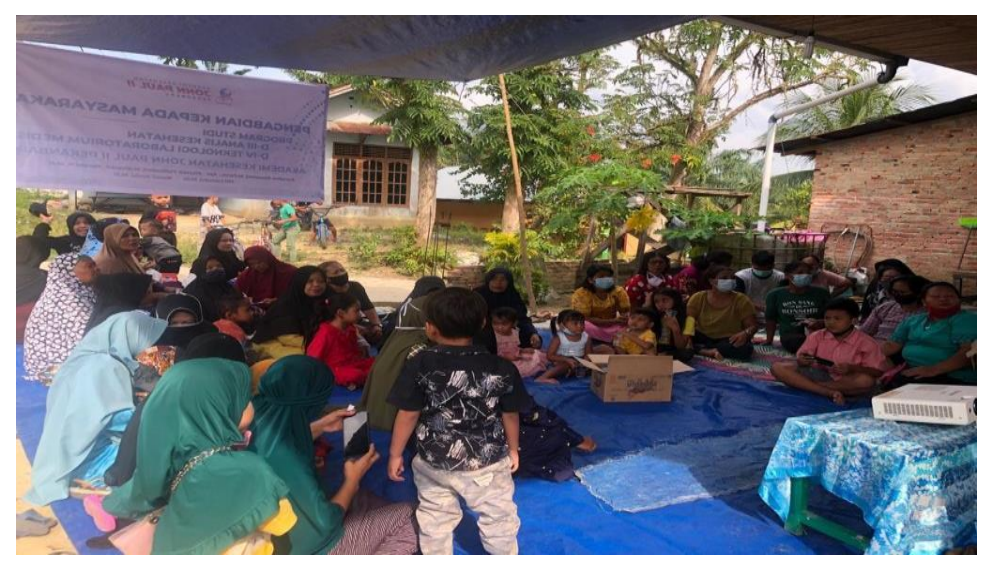

Gambar 1. Kegiatan pengabdian pemberian edukasi hiperkolesterolemia 

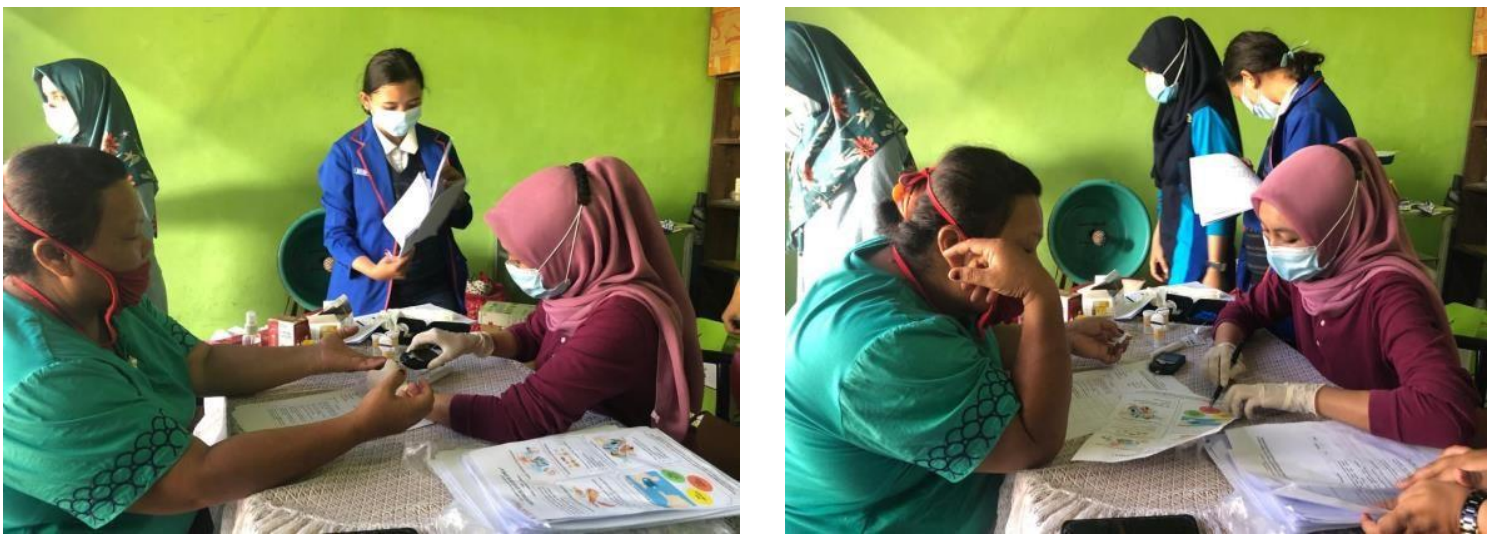

Gambar 2. Pemeriksaan Kolesterol dan Pemberian Edukasi hiperkolesterolemia kepada masyarakat Kelurahan Muara Fajar Timur Pekanbaru

Pemeriksaan kolesterol dan pemberian edukasi hiperkolesterolemia diikuti oleh 38 orang masyarakat Kelurahan Muara Fajar Timur Pekanbaru. Peserta yang mengikuti kegiatan ini seluruhnya berjenis kelamin wanita dengan usia > 30 tahun, peserta pria tidak mengikuti kegiatan ini karena kegiatan dilaksanakan pada saat jam kerja masyarakat kelurahan Muara Fajar Timur. Sebagian besar masyarakat Muara Fajar Timur bekerja sebagai pemulung yang bekerja dari pagi hingga sore. Hasil data pengisisan kuesioner disajikan pada Tabel 1 dan hasil pemeriksaan kolesterol disajikan pada Tabel 2.

Tabel 1. Data Pengisian Kuesioner Pengabdian

\begin{tabular}{|c|c|c|c|}
\hline \multirow{2}{*}{ No } & \multirow{2}{*}{ Pertanyaan } & \multicolumn{2}{|c|}{ Jawaban } \\
\hline & & Ya & Tidak \\
\hline 1 & $\begin{array}{l}\text { Apakah bapak/ibu sering mengkonsumsi makanan tinggi lemak seperti: } \\
\text { daging merah (babi, domba, sapi), jeroan, gorengan, kerang }\end{array}$ & $76,32 \%$ & $23,68 \%$ \\
\hline 2 & Apakah bapak/ibu sering melakukan aktivitas fisik atau berolahraga & $26,32 \%$ & $73,68 \%$ \\
\hline 3 & Apakah bapak/ibu merokok & $0 \%$ & $100 \%$ \\
\hline 4 & Apakah bapak/ibu sering mengkonsumsi alkohol & $0 \%$ & $100 \%$ \\
\hline 5. & $\begin{array}{l}\text { Apakah bapak/ibu pernah dikatakan oleh dokter/ petugas kesehatan } \\
\text { mempunyai kolesterol tinggi? }\end{array}$ & $13,16 \%$ & $86,84 \%$ \\
\hline 6. & $\begin{array}{l}\text { Apakah di keluarga Anda (orang tua atau saudara kandung) ada yang } \\
\text { mempunyai kolesterol tinggi? }\end{array}$ & $18,42 \%$ & $81,57 \%$ \\
\hline 7. & Apakah saudara memahami tentang bahayanya kadar kolesterol tinggi? & 28,95 & $71,05 \%$ \\
\hline
\end{tabular}

Tabel 2. Distribusi frekuensi kategori kolesterol berdasarkan usia pada masyarakat kelurahan Muara Fajar Timur Pekanbaru

\begin{tabular}{|c|c|c|c|c|c|c|c|}
\hline \multirow[t]{2}{*}{ No } & \multirow[t]{2}{*}{$\begin{array}{c}\text { Usia } \\
\text { (tahun) }\end{array}$} & \multicolumn{2}{|c|}{$\begin{array}{l}\text { Kolesterol Normal } \\
(<200 \mathrm{mg} / \mathrm{dl})\end{array}$} & \multicolumn{2}{|c|}{$\begin{array}{l}\text { Hiperkolesterolemia } \\
\text { (> } 200 \mathrm{mg} / \mathrm{dl})\end{array}$} & \multicolumn{2}{|c|}{ Total } \\
\hline & & $\mathrm{n}$ & $\%$ & $\mathrm{n}$ & $\%$ & $\mathrm{~N}$ & $\%$ \\
\hline 1 & $30-40$ th & 4 & 21,05 & 15 & 78,95 & 19 & 100 \\
\hline 2 & $41-50$ th & 4 & 40 & 6 & 60 & 10 & 100 \\
\hline 3 & $>50$ th & 1 & 11,11 & 8 & 88.89 & 9 & 100 \\
\hline Total & & 9 & 23,68 & 29 & 76,32 & 38 & 100 \\
\hline
\end{tabular}

Hasil yang diperoleh dari pemeriksaan kolesterol terhadap seluruh peserta didapatkan sebanyak $76,32 \%$ atau 29 orang peserta memiliki kadar kolesterol > 200 mg/dl. Berdasarkan edukasi, pengisian 
angket dan wawancara yang dilakukan, bahwa sebagian besar masyarakat tidak memahami akan bahayanya hiperkolesterolemia. Masyarakat Muara Fajar Timur juga memiliki pola hidup yang tidak sehat yaitu jarang berolah raga dan seringnya mengonsumsi makanan tinggi lemak seperti daging babi, jeroan dan makanan yang mengandung santan. Konsumsi makanan tinggi lemak menjadi penyebab utama meningkatnya kadar kolesterol total di dalam darah (Yoeantafara \& Martini, 2017). Aktivitas fisik yang rendah sangat mempengaruhi kadar kolesterol didalam darah akibatnya terjadi peningkatan kolesterol darah kan berpengaruh terhadap peningkatan kadar kolesterol darah (Agustiyanti et al., 2017).

Hasil pemeriksaan kolesterol didapatkan bahwa peserta yang memiliki kadar kolesterol diatas normal (> $200 \mathrm{mg} / \mathrm{dl}$ ) terdapat pada usia 30-40 tahun dengan jumlah terbanyak yaitu 15 orang. Berdasarkan wawancara yang dilakukan, selain faktor kurangnya aktivitas fisik dan seringnya mengonsumsi makanan tinggi lemak, faktor penggunaan kontrasepsi diduga menjadi penyebab peningkatnya kolesterol pada sebagian wanita. Usia 30-40 tahun merupakan usia yang produktif bagi seorang wanita karena belum mengalami menopause. Penggunaan kontrasepsi hormonal dapat menekan HDL dan meningkatkan LDL didalam darah sehingga dapat menyebabkan peningkatan kolesterol didalam darah (Agustiyanti et al., 2017).

\section{SIMPULAN}

Berdasarkan hasil pengabdian, 29 responden memiliki kadar kolesterol > $200 \mathrm{mg} / \mathrm{dl}$ dan 9 responden $<200 \mathrm{mg} / \mathrm{dl}$. Hal ini disebabkan karena pola hidup masyarakat yang tidak sehat seperti jarang berolahraga dan sering mengonsumsi makanan tinggi lemak, serta kurangnya pengetahuan tentang bahaya dari hiperkolesterolemia. Pemeriksaan kolesterol dan edukasi akan bahayanya hiperkolesterolemia sangat bermanfaat bagi masyarakat Kelurahan Muara Fajar Timur Pekanbaru. Masyarakat dapat memahami penyebab, tanda, gejala dan faktor resiko dari hiperkolesterolemia. Masyarakat juga memahami pentingnya mengetahui kadar kolesterol darah dan upaya pencegahan hiperkolesterolemia sehingga dapat meningkatkan kesadaran untuk menjaga pola hidup yang sehat.

\section{UCAPAN TERIMA KASIH}

Terima kasih kepada seluruh masyarakat Muara Fajar Timur Pekanbaru yang telah berkonstribusi pada kegiatan ini. Terima kasih untuk seluruh civitas Akademi Kesehatan John Paul II Pekanbaru atas dukungan sehingga kegiatan ini dapat terlaksana dengan baik.

\section{DAFTAR PUSTAKA}

Agustiyanti, P. N., Pradigdo, S. F., \& Aruben, R. (2017). Hubungan Asupan Makanan, Aktivitas Fisik Dan Penggunaan Kontrasepsi Hormonal Dengan Kadar Kolesterol Darah (Studi pada Wanita Keluarga Nelayan Usia 30 - 40 Tahun di Tambak Lorok, Semarang Tahun 2017). Jurnal Kesehatan Masyarakat, 5(4), 737-743. 
Budiatmaja, A. C., \& Noer, E. R. (2014). Pengaruh Pemberian Jus Buah Naga Merah (Hylrocereus polyrhizus) Terhadap Kadar Kolesterol Total Pria Hiperkolesterolemia. Journal of Nutrition College, 3(4), 655-664.

Herman, S. I., Syukri, M., \& Efrida. (2015). Artikel Penelitian Hubungan Faktor Risiko yang dapat Dimodifikasi dengan Kejadian Penyakit Jantung Koroner di RS Dr . M . Djamil Padang. Jurnal Kesehatan Andalas, 4(2), 369-375.

Jempormase, F., Bodhi, W., \& Kepel, B. J. (2016). Prevalensi hiperkolesterolemia pada remaja obes di Kabupaten Minahasa. Jurnal E-Biomedik, 4(1), 25-29.

Kumar, V., Abbas, A. K., \& Aster, J. C. (2014). Buku Ajar Patologi Robbins (9th ed) (I. M. Nasar \& C. Santoso (eds.); 9 ed). Elsevier.

Lina, N., \& S Dian. (2019). Deteksi dini penyakit jantung koroner di Pos Pembinaan Terpadu Penyakit Tidak Menular (POSBINDU PTM). Jurnal Kesehatan Komunitas Indonesia, 15(1), 93-104.

Maryati, H. (2017). Hubungan Kadar Kolesterol dengan Tekanan Darah Penderita Hipertensi Di Dusun Sidomulyo Desa Rejoagung Kecamatan Ploso Kabupaten Jombang. Hubungan Kadar Kolesterol Dengan Tekanan Darah Penderita Hipertensi Di Dusun Sidomulyo Desa Rejoagung Kecamatan Ploso Kabupaten Jombang, 8(2), 128-137.

Setiadi, A. P., \& Halim, S. V. (2018). Penyakit Kardiovaskular Seri Pengobatan Rasional. Graha Ilmu.

Setyaningrum, R. A., N. Susanto, H. Yuningrum, \& N. A. P. Wati. (2019). Faktor Yang Berhubungan Dengan Hiperkolesterolemia Di Dusun Kopat, Desa Karangsari, Kecamatan Pengasih, Kabupaten Kulon Progo, DIY. Seminar Nasional UNRIYO, 1-11.

Subandrate, Susilawati, \& Safyudin. (2019). Pendampingan Usaha Pencegahan dan Penanganan Hiperkolesterolemia Pada pelajar. Jurnal Arsip Pengabdian Masyarakat, 1(1), 1-7.

Wihastuti, T. A., Andarini, S., \& Heriansyah, T. (2016). Patofisiologi dasar keperawatan penyakit jantung koroner : inflasi vaskular. UB Press.

Yani, M. (2015). Mengendalikan Kadar Kolesterol Pada Hiperkolesterolemia. Jurnal Olahraga Prestasi, 11(2), 1-7. Yoeantafara, A., \& Martini, S. (2017). Pengaruh Pola Makan Terhadap Kadar Kolesterol Total. Media Kesehatan Masyarakat Indonesia, 13(4), 304-309. 